\title{
PENDEKATAN FAMILY CENTERED CARE DENGAN KEPUASAN KERJA PERAWAT DI RSUD. H. A. SULTHAN DG. RADJA
}

\author{
${ }^{1}$ Endang Nurul Mukmin \\ IIlhamsyah, \\ ${ }^{3}$ Edison Siringoringo
}

1Program Studi S1 Keperawatan Stikes Panrita Husada Bulukumba, Indonesia

${ }^{2}$ Departemen Keperawatan Manajemen, Universitas Islam Negeri Makassar, Indonesia

${ }^{3}$ Departemen Keperawatan Manajemen, Stikes Panrita Husada Bulukumba, Indonesia

\author{
Alamat Koresponden: \\ Endang Nurul Mukmin \\ Jl.Nenas, Kel.Loka, \\ Kec. Ujung Bulu, \\ Kabupaten Bulukumba. \\ Hp. 082190743945 \\ Email: Endangnurulmukmin@gmail.com
}




\begin{abstract}
ABSTRAK
Family Centered Care adalah perawatan keluarga yang dilakukan pada sebuah pendekatan untuk perawatan kesehatan. Kepuasan kerja merupakan hasil persepsi karyawan tentang sejauh mana pekerjaan mereka dapat memberikan keadaan emosi. Stres kerja perawat yang disebabkan oleh beban kerja dapat mengakibatkan ketidakpuasan kerja pada perawat, jika dilihat dari lingkungan kerja yang membuat perawat merasa tidak nyaman dalam bekerja, disebabkan karena sebagian dari orangtua pasien menolak untuk diajak bekerjasama dalam melakukan perawatan terhadap pasien, orangtua mereka beranggapan bahwa hal tersebut bukanlah pekerjaannya melainkan pekerjaan seorang perawat. Tujuan penelitian ini untuk mengetahui hubungan pendekatan Family Centered Care pada pasien anak dengan kepuasan kerja perawat di ruang perawatan mawar RSUD. H. A. Sulthan Daeng Radja Kabupaten Bulukumba Tahun 2019. Desain penelitian menggunakan desain cross sectional. Populasi dalam penelitian adalah semua perawat pasien anak yang berjumlah 52 orang di ruang perawatan mawar RSUD. H. A. Sulthan Daeng Radja Kabupaten Bulukumba dengan tekhnik pengambilan sampel menggunakan puprposive sampling, Jumlah sampel dalam penelitian ini sebanyak 30 responden. Data diperoleh melalui lembar kuesioner yang diadopsi dari peneliti lain untuk responden. Analisa data menggunakan uji Chi-square alternatif Fisher's dengan taraf kemaknaan $p=0,05$. Hasil penelitian menunjukkan bahwa pelaksanaan pendekatan Family Centered Care pada pasien anak kurang baik sebanyak 18 responden $(60,0 \%)$ dan kepuasan kerja perawat didapatkan hasil puas sebanyak 16 responden $(53,3 \%)$. Hasil analisa menggunakan aplikasi SPSS didapatkan nilai $\rho=0,001$. Kesimpulan yaitu Terdapat hubungan antara pendekatan Family Centered Care pada pasien anak dengan kepuasan kerja perawat di ruang perawatan mawar RSUD. H. A. Sulthan Daeng Radja Kabupaten Bulukumba tahun 2019. Diharapkan Penelitian ini dapat dijadikan sebagai tambahan pengetahuan untuk mahasiswa dalam mata kuliah manajemen keperawatan.
\end{abstract}

Kata Kunci: Family Centered Care, Kepuasan Kerja Perawat

\begin{abstract}
Family Centered Care is family care carried out on an approach to health care. Job satisfaction is the result of employees' perceptions of the extent to which their work can provide an emotional state. Nurse work stress caused by workload can lead to work dissatisfaction with nurses, if viewed from a work environment that makes nurses feel uncomfortable at work, because some of the patient's parents refuse to be invited to cooperate in caring for patients, their parents assume that it is not his job but the work of a nurse. The purpose of this study was to determine the relationship of the Family Centered Care approach in pediatric patients with nurse job satisfaction in the rose care room of RSUD. H. A. Sulthan Daeng Radja of Bulukumba Regency in 2019. The research design used a cross sectional design. The population in this study were all child patient nurses, amounting to 52 people in the rose hospital care room. H. A. Sulthan Daeng Radja of Bulukumba Regency with a sampling technique using purposive sampling, the number of samples in this study were 30 respondents. Data obtained through questionnaire sheets adopted from other researchers for respondents. Data analysis used Fisher's alternative Chi-square test with significance level $p=0.05$. The results showed that the implementation of the Family Centered Care approach in pediatric patients was not good as many as 18 respondents (60.0\%) and the job satisfaction of nurses was satisfied as many as 16 respondents (53.3\%). The results of the analysis using the SPSS application obtained the value of $\rho=0.001$. The conclusion is that there is a relationship between the Family Centered Care approach in pediatric patients with nurse job satisfaction in the rose care room of RSUD. H. A. Sulthan Daeng Radja of Bulukumba Regency in 2019. It is hoped that this research can be used as additional knowledge for students in nursing management courses.
\end{abstract}

Keywords: Family Centered Care, Nurse Job Satisfaction 
PENDAHULUAN

Perawat merupakan ujung tombak baik tidaknya pelayanan kesehatan yang diberikan kepada pasien. Hal ini disebabkan karena jumlahnya yang dominan dari seluruh tenaga yang ada di Rumah Sakit yang bertugas merawat dan menjaga pasien selama 24 jam sehari. Peran perawat dalam meminimalkan stres akibat hospitalisasi pada anak adalah sangat penting. Perawat perlu memahami konsep stres hospitalisasi dan prinsipprinsip asuhan keperawatan melalui pendekatan proses keperawatan. Hal ini sangat penting untuk menunjang proses keperawatan. Orang tua diharapkan dapat berpartisipasi dalam merawat anak yang sakit, terutama dalam perawatan yang bisa dilakukan olehnya itu dengan pendekatan Family Center Care dapat menjaid solusi (Ambarwati \& Nasution, 2015).

\section{Family Centered Care adalah} perawatan keluarga yang dilakukan pada sebuah pendekatan untuk perawatan kesehatan yang membentuk kebijakan, program, desain fasilitas, yang memberikan kesempatan terhadap interaksi staf dan keluarga setiap hari (Nurlaila, Utami, \& Cahyani, 2018). Kepuasan kerja merupakan hasil persepsi karyawan tentang sejauh mana pekerjaan mereka dapat memberikan keadaan emosi. Maka sangat penting bagi pengelola perusahaan/

organisasi

untuk memperhatikan kepuasan kerja karyawan agar tercapai efisiensi dan efektivitas organisasi melalui karyawan yang puas dan berkinerja tinggi (Noermijati, 2013).

Berdasarkan data WHO, pada tahun 2012 pasien yang dirawat di Rumah Sakit sekitar 52\% adalah anak-anak dengan beragam penyakit yang dideritanya. Berdasarkan data kementrian kesehatan RI tahun 2012 menunjukkan bahwa jumlah pasien anak yang dirawat di Rumah Sakit perawatan anak rata-rata130-153 anak per bulannya (Kemenkes, 2012).

Berdasarkan hasil pendataan awal yang didapat dari ruang Rekam Medik RSUD H. A. Sulthan Daeng Radja Kabupaten Bulukumba dari bulan JanuariSeptember Tahun 2018 jumlah anak yang dirawat di ruang perawatan mawar adalah rata-rata $>100$ anak setiap bulannya dan berdasarkan hasil pendataan awal yang dilakukan di ruang perawatan mawar RSUD H. A. Sulthan Daeng Radja Kabupaten Bulukumba pada bulan Desember Tahun 2018 jumlah perawat anak di ruang perawatan mawar sebanyak 52 orang perawat.

Diterjemahkan dari bahasa inggris Family Centered Care adalah perawatan yang berpusat pada keluarga atau layanan yang berpusat pada keluarga yaitu suatu pendekatan yang memberikan pandangan 
luas tentang bagaimana bekerja dengan anak-anak dan keluarga (Hernilawati, 2013).

Dari hasil penelitian ini di dukung oleh beberapa penelitian yang dilakukan oleh (Kusumaningrum, 2010) dengan judul aplikasi dan strategi konsep Family Centered Care pada hospitalisasi anak prasekolah. Adapun hasil penelitiannya menunjukkan bahwa penerapan Family Centered Care dalam perawatan anak prasekolah melibatkan semua aspek dari kebijakan, fasilitas dan perawat (staf) menjadi satu-kesatuan sinergi dalam perawatan anak dan penelitian lain yang dilakukan oleh (SAFITRI, 2014) dengan judul pengaruh pendekatan Family Centered Care oleh perawat terhadap tingkat kooperatif anak usia prasekolah (35 tahun) dalam pemberian tindakan keperawatan di RSUD Ngudi Waluyo Wlingi. Adapun hasil penelitiannya menunjukkan bahwa terdapat pengaruh pendekatan Family Centered Care yang dilakukan oleh perawat terhadap tingkat kooperatif anak.

Kepuasan kerja merupakan hasil persepsi karyawan tentang sejauh mana pekerjaan mereka dapat memberikan keadaan emosi. Maka sangat penting bagi pengelola perusahaan/organisasi untuk memperhatikan kepuasan kerja karyawan agar tercapai efisiensi dan efektivitas organisasi melalui karyawan yang puas dan berkinerja tinggi (Noermijati, 2013).

Dari hasil penelitian ini di dukung oleh beberapa penelitian yang dilakukan oleh (Sinaga, 2015) dengan judul pengaruh stres kerja dan lingkungan kerja terhadap kepuasan kerja perawat Rumah Sakit. Adapun hasil penelitiannya menunjukkan bahwa stres kerja dan lingkungan kerja memiliki pengaruh yang signifikan terhadap kepuasan kerja perawat Rumah Sakit HKBP Belige. Dan hasil penelitian lain yang dilakukan oleh (Wolo et al., 2017) dengan judul faktor-faktor yang mempengaruhi kepuasan kerja perawat pada RSUD TNI AU Yogyakarta. Adapun hasil penelitiannya menunjukkan bahwa secara simultan variabel gaji, promosi, supervisi, rekan sekerja, pekerjaan itu sendiri, dan lingkungan kerja mempunyai pengaruh yang signifikan terhadap kepuasan kerja perawat di RSUD TNI AU yogyakarta.

Tujuan penelitian ini adalah untuk mengetahui hubungan antara pendekatan Family Cenetered Care pada pasien anak dengan kepuasan kerja perawat di ruang perawatan mawar RSUD. H. A. Sulthan Daeng Radja Kabupaten Bulukumba Tahun 2019. 


\section{METODE}

Jenis penelitian ini merupakan penelitian kuantitatif dengan menggunakan pendekatan Cross Sectional yang bertujuan untuk menghubungkan antara variabel sebab atau risiko dan akibat atau kasus yang terjadi pada obyek penelitian yang di ukur dan dikumpulkan secara simultan (dalam waktu yang bersamaan).

(Sugiyono, 2014) Bahwa populasi merupakan wilayah generalisasi yang terdiri dari sebuah obyek. Populasi dalam penelitian ini adalah perawat pasien anak yang berjumlah 52 orang di ruang perawatan mawar RSUD H. A. Sulthan Daeng Radja Kabupaten Bulukumba.

Pengambilan sampel dalam penelitian ini menggunakan Porposive Sampling yaitu pengambilan sampel dilakukan atas dasar pertimbangan peneliti yang menganggap unsur-unsur yang dikehendaki telah ada dalam anggota sampel yang diambil. Sampel dalam penelitian ini yaitu sebanyak 30 responden yang didapatkan berdasarkan dengan rumus besar sampel menurut (Sugiyono, 2014).

Instrumen dalam penelitian ini adalah kuesioner (angket). Kuesioner digunakan untuk mengumpulkan data tentang bagaimana pendekatan Family Centered Care pada pasien anak yang telah dilakukan oleh perawat dan bagaimana kepuasan kerja perawat dalam melibatkan keluarga pasien setiap melakukan perawatan kepada pasien.

Data dianalisis berdasarkan skala ukur dan tujuan penelitian dengan menggunakan perangkat lunak program komputerisasi. Data dianalisis secara : (1). Analisis Univariat, Analisis dilakukan untuk melihat proporsi. (2). Analisis Bivariat, Uji bivariat dilakukan untuk mencari hubungan antara variabel independen dan variabek dependen dengan uji yang digunakan adalah uji fisher's exact test sebagai alternative. Kemaknaan yang diterima apabila $\mathrm{p}<0,05$.

\section{HASIL}

Berdasarkan Tabel 1 menunjukkan sebagian besar responden berjenis kelamin perempuan sebanyak 30 resonden $(100,0 \%)$. Pada umur responden yang paling tinggi adalah yang berada pada kategori dewasa awal sebanyak 16 responden $(53,3 \%)$ sedangkan yang paling rendah adalah remaja akhir sebanyak 5 responden (16,7\%). Pada tingkat pendidikan terakhir responden yang berpendidikan tinggi didapatkan pada responden dengan kategori DIII Keperawatan sebanyak 21 responden $(69,7 \%)$ sedangkan yang paling rendah adalah S1 keperawatan + Ners sebanyak 9 responden $(30,3 \%)$. Sebagian besar lama 
kerja responden adalah yang telah bekerja selama 4-5 tahun sebanyak 18 responden $(60,0 \%)$ dan yang paling rendah adalah responden yang telah bekerja selama 2-3 tahun sebanyak 12 responden $(40,0 \%)$.

Berdasarkan Tabel 2 menunjukkan distribusi frekuensi responden berdasarkan pelaksanaan pendekatan Family Centered Care pada pasien anak diruang perawatan mawar RSUD H. A. Sulthan Daeng Radja Kabupaten Bulukumba sebagian besar menunjukkan pelaksanaan yang kurang baik sebanyak 18 responden $(60,0 \%)$ sedangkan pelaksanaan dengan baik hanya sebanyak 12 responden (40,0\%). Pada Kepuasan kerja perawat, sebagian besar perawat yang merasa puas sebanyak 16 responde $(53,3 \%)$ sedangkan perawat yang merasa tidak puas hanya sebanyak 14 responden $(46,7 \%)$.

Berdasarkan Tabel 3 menunjukkan bahwa pelaksanaan pendekatan Family Centered Care pada pasien anak didapatkan hasil baik dengan kepuasan kerja perawat tidak puas sebanyak 10 responden $(33,4 \%)$. Kepuasan Kerja Perawat hasilnya puas sebanyak 2 responden $(6,6 \%)$. Sedangkan Pelaksanaan pendekatan Family Centered Care pada pasien anak didapatkan hasil kurang baik dengan kepuasan kerja perawat tidak puas sebanyak 4 responden $(46,7 \%)$ dan hasil kurang baik dengan kepuasan kerja perawat puas sebanyak 14 responden $(46,7 \%)$. Hasil uji statistik yaitu uji ChiSquare yang dilihat dari fisher's exact test diperoleh angka yang signifikan atau nilai probabilitas $(0,001)$ standart signifikan jauh lebih rendah dari 0,05 atau $(\rho<\alpha)$, sehingga $\mathrm{H} 1$ diterima dan $\mathrm{H} \alpha$ ditolak yang berarti terdapat hubungan antara Pendekatan Family Centered Care Pada Pasien Anak dengan Kepuasan Kerja Perawat di Ruang Perawatan Mawar RSUD. H. A. Sulthan Daeng Radja Kabupaten Bulukumba.

\section{PEMBAHASAN}

Pada penelitian ini terlihat bahwa terdapat hubungan antara pendekatan Family Centered Care pada pasien anak dengan kepuasan kerja perawat di ruang perawatan mawar RSUD. H. A. Sulthan Daeng Radja Kabupaten Bulukumba Tahun 2019.

Dari hasil uji statistik yaitu uji fisher's exact test diperoleh angka yang signifikan dengan nilai $p=0,001$, sehingga $\mathrm{H} 1$ diterima dan $\mathrm{H} \alpha$ ditolak yang berarti terdapat hubungan antara Pendekatan Family Centered Care Pada Pasien Anak dengan Kepuasan Kerja Perawat di Ruang Perawatan Mawar RSUD. H. A. Sulthan Daeng Radja Kabupaten Bulukumba Tahun 2019. 
Adapun asumsi peneliti terkait dengan hasil penelitian bahwa pelaksanaan pendekatan Family Centered Care kepada pasien anak dengan kepuasa kerja perawat memiliki hubungan kerja yang signifikan. Karena dengan melibatkan keluarga pasien dalam perawatan anak, maka kerjasama akan terjalin antara perawat dan keluarga pasien, sehingga proses untuk mempercepat kesembuhan terhadap pasien dapat dilakukan.

Hal ini didukung oleh (Supartini, 2014) didalam bukunya (Buku Ajar Konsep Keperawatan Anak) yang mengatakan bahwa dalam melakukan perawatan kepada pasien anak perawat harus mementingkan dan melibatkan peran penting dari keluarga pasien, karena dukungan keluarga akan membangun kekuatan dalam meningkatkan pola normal yang ada dalam keseharian anak dan dapat mempercepat proses kesembuhan karena keluarga lebih mengenali pasien dan mengetahui cara untuk membuat pasien merasa nyaman selama dirawat di Rumah Sakit.

Penelitian ini juga didukung oleh hasil penelitian yang telah dilakukan oleh (YULIANA, 2014) dengan judul hubungan pendekatan Family Centered Care pada pasien anak usia prasekolah dengan kepuasan kerja perawat diruang anak RSUD wilayah Blitar yang mengatakan bahwa ada hubungan antara pendekatan Family Centered Care dengan kepuasan kerja perawat di ruang anak RSUD wilayah Blitar dengan nilai $\rho=$ $0,038(\rho<\alpha)$.

\section{KESIMPULAN DAN SARAN}

Terdapat hubungan antara pendekatan Family Centered Care pada pasien anak dengan kepuasan kerja perawat di ruang perawatan mawar RSUD. H. A. Sulthan Daeng Radja Kabupaten Bulukumba Tahun 2019. Hasil penelitian ini diharapkan dapat menjadi menjadi pembelajaran bagi perawat untuk meningkatkan kerjasamanya dengan keluarga pasien dan diharapkan untuk keluarga agar selalu berada di samping pasien agar pasien tidak mengalami trauma karena berada di tempat asing.

\section{DAFTAR PUSTAKA}

Ambarwati, R. F., \& Nasution, N. (2015). Buku Pintar Asuhan Keperawatan Bayi Dan Balita. Jalan Randubelang No.115 Yogyakarta: Cakrawala Ilmu.

Asmadi. (2014). Konsep Dasar Keperawatan. Jakarta: EGC.

Barahama, K.F., Katuuk, M., Oroh, W.M., 2019. HUBUNGAN BEBAN KERJA DENGAN KEPUASAN KERJA PERAWAT DI RUANGAN 
PERAWATAN DEWASA RSU

GMIM PANCARAN KASIH

MANADO. J. KEPERAWATAN 7.

TERHADAP KINERJA PERAWAT

PKU MUHAMMADIYAH

YOGYAKARTA UNIT 2. J. Manaj.

Bisnis Indones. JMBI 6, 23-35.

Cahyani, D., 2017. PENGARUH KEPUASAN KERJA DAN STRES KERJA

Cockcroft. (2012). Patient And Family Centered Care and The Pediatrician's Role. California: Blackwell.

De Fretes, F., 2012. Hubungan Family Centered Care dengan Efek Hospitalisasi pada Anak di Ruang Dahlia Rumah Sakit Panti Wilasa Citarum, Semarang.

Depkes, \& RI. (2015).

Dharma, K. K. (2017). Metodologi Penelitian Keperawatan. Dalam Panduan Melaksanakan dan Menerapkan Hasil Penelitian (hal. 389). Jl.MAN 6 No.74 Kramat Jati -Jakarta Timur: CV. Trans Info Media.

Hakim, A., Yassir, M., Nur, M., 2014. Pengaruh Hubungan Interpersonal dan Lingkungan Kerja terhadap Kepuasan Kerja Perawat di Ruangan UGD RSUD Salewangang Maros. J. Ilm. Kesehat. Diagn.
Hamid, S. (2014). Manajemen Sumber Daya Manusia Lanjutan. Jl. Elang 6, No 3, Sardonoharjo, Ngaglik, Sleman, Jl. Kaliurang Km. 9,3Yogyakarta : DEEPUBLISH.

Hernilawati. (2013). Konsep Dan Proses Keperawatan Keluarga. $\mathrm{Jl}$. Diponegoro Perumahan Anugrah Ananda II D/L Kalampa Kelurahan Kalabbirang Kecamatan Patallassang Kabupaten Takalar Sulawesi Selatan: Pustaka As Salam.

Hidayat, A. A. (2014). Metode Penelitian Keperawatan dan Teknik Analisa Data. Jl. Raya Lenteng Agung No. 101 Jagakarsa, Jakarta Selatan 12610: Salemba Medika.

Hulinggi, I., Masi, G., Ismanto, A.Y., 2018. HUBUNGAN SIKAP PERAWAT DENGAN STRES AKIBAT HOSPITALISASI PADA ANAK USIA PRA SEKOLAH DI RSU PANCARAN KASIH GMIM MANADO. J. KEPERAWATAN 6.

Ibrahim, M., Oldemar, O., 2015. Pengaruh Lingkungan Kerja terhadap Kepuasan Kerja Perawat Rumah Sakit Syafira Pekanbaru. J. Online Mhs. Fak. Ilmu Sos. Dan Ilmu Polit. Univ. Riau 2.

Iskandar, \& Yuhansyah. (2018). Pengaruh Motivasi Dan Ketidakamanan Kerja Terhadap Penilaian Kerja Yang 
Berdampak Kepada Kepuasan Kerja.

Pondok Maritim Indah Blok PP-7,

Balas Klumprik, Wiyung, Kota

Surabaya: Media Sahabat Cendekia.

Kasmiruddin, K., Sinaga, D.S., 2015.

Pengaruh Stres Kerja dan Lingkungan Kerja terhadap

Kepuasan Kerja Perawat Rumah

Sakit (Studi Kasus pada Rs. Hkbp

Balige, Kabupaten Toba Samosir,

Sumatera Utara). J. Online Mhs.

Fak. Ilmu Sos. Dan Ilmu Polit. Univ.

Riau 2.

Kemenkes. (2012). Data Anak Indonesia.

Kusumaningrum, A., 2010. Aplikasi dan strategi konsep family centered care pada hospitalisasi anak pra sekolah.

J. Kedokt. Dan Kesehat. 42.

Noermijati. (2013). Kajian Tentang Aktualisasi Teori Herzberg, Kepuasan Kerja Dan Kinerja Spiritual Manajer Operasional. Jl. Veteran, Malang 65145 Indonesia: Universitas Brawijaya Press (UB Press).

Nurlaila, Utami, W., \& Cahyani, T. (2018). Buku Ajar Keperawatan Anak. Jl. Wiratama No. 50, Tegalrejo, Yogyakarta, 55244: LeutikaPrio.

Nursalam, \& Efendy, F. (2014). Dalam Pendidikan Dalam Keperawatan. Jakarta: Salemba Medika.
Rifiani, N., \& Sulihandri, H. (2013). Prinsip-Prinsip Dasar Keperawatan. Jakarta: Dunia Cerdas.

Rusmawati, A., Kristina, T.N., Sujianto, U., $2016 . \quad$ UPAYA MENINGKATKAN

KEMAMPUAN PERAWAT DALAM MENERAPKAN PATIENT CENTERED CARE (PCC) DI RUMAH SAKIT (STUDI DI RSUD DR. HARJONO PONOROGO DAN RSUD DR. ISKAK TULUNGAGUNG.

Saefullah. (2012). Psikologi Perkembangan Dan Pendidikan. Bandung: CV Pustaka Setia.

SAFITRI, D.L., 2014. PENGARUH PENDEKATAN FAMILY CENTERED CARE OLEH PERAWAT TERHADAP TINGKAT KOOPERATIF ANAK USIA PRASEKOLAH (3-5 TAHUN) DALAM PEMBERIAN TINDAKAN KEPERAWATAN DI RSUD NGUDI WALUYO WLINGI.

Saputro, H., \& Farin, I. (2017). Anak Sakit Wajib Bermain di rumah Sakit. Jl. Cemara 25 Rt.01 RW.02 Ds/Kec. Sukorejo. Ponorogo: Forum Ilmiah Kesehatan (FORIKES).

Sefrina, A., \& Purnama, C. S. (2012). Mengenal, Mencegah, Menangani 
Berbagai Penyakit pada Bayi dan Balita. Jl. Raya Munjul No. 1 Cipayung - Jakarta Timur: Dunia Sehat.

Sinaga, D.S., 2015. PENGARUH STRES KERJA DAN LINGKUNGAN KERJA TERHADAP KEPUASAN KERJA PERAWAT RUMAH SAKIT (Studi Kasus Pada RS. HKBP Balige, Kabupaten Toba Samosir, Sumatera Utara). J. Online Mhs. JOM Bid. Ilmu Sos. Dan Ilmu Polit. 2, 1-15.

Suarli, S., \& Bahtiar, Y. (2012). Manajemen Keperawatan dengan Pendekatan Praktis. Jl. H. Baping Raya No.100 Ciracas, Jakarta: Erlangga.

Sugiyono, D. P. (2014). STATISTIKA UNTUK PENELITIAN. Jl. Gegerkalong Hilir No 84 Bandung: ALFABETA, CV.

Sunaengsih, C. (2017). Buku Ajar Pengelolaan Pendidikan. Jl. Mayor Abdurrahman No.211 Sumedang: UPI Sumedang Press.

Supartini, Y. (2014). Buku Ajar Konsep Dasar Keperawatan Anak. Jakarta: Buku Kedokteran EGC.

Suza, D.E., 2015. Family-Centered Care Model untuk Menurunkan Dampak Hospitalisasi Anak dengan Penyakit
Kanker di Medan, Sumatera Utara. Idea Nurs. J. 6, 15-24.

Tahsinia, N., n.d. "Faktor-Faktor yang Berhubungan dengan Kepuasan Kerja Perawat di RS. Rumah Sehat Terpadu, Parung, Bogor, Tahun 2013.

Tina Shinta, P., Setyarini, N.E.A., Prtahama, M.D., n.d. HUBUNGAN PENGETAHUAN DENGAN SIKAP PERAWAT DALAM PELAKSANAAN FAMILY CENTERED CARE DI RUANG RAWAT INAP ANAK.

Yugistyowati, A., Santoso, S., 2018. Pengetahuan Perawat Tentang Family Centered-Care Dengan Sikap Dalam Pemberian Asuhan Keperawatan Di Ruang Rawat Inap Anak. J. Keperawatan Respati Yogyak. 5, 39-44.

Wikipedia Bahasa Indonesia, e. b. (2014). Undang-Undang Nomor 38 .

Wolo, P.D., Trisnawati, R., Wiyadi, W., 2017. FAKTOR FAKTOR YANG MEMPENGARUHI KEPUASAN KERJA PERAWAT PADA RSUD TNI AU YOGYAKARTA. J. Manaj. Dayasaing 17, 78-87. 
Tabel 1

Karakteristik Responden Berdasarkan Jenis Kelamin, Umur, Pendidikan Terakhir dan Lama Kerja

\begin{tabular}{ccc}
\hline Karakteristik Responden & f & $\%$ \\
\hline Jenis Kelamin & 0 & 0 \\
\hline Laki-Laki & 30 & 100,0 \\
Perempuan & & \\
\hline Umur & 5 & 16,7 \\
\hline Remaja Akhir & 16 & 53,3 \\
Dewasa Awal & 9 & 30,3 \\
Dewasa Akhir & & \\
\hline Pendidikan Terakhir & 21 & 69,7 \\
\hline DIII Keperawatan & 9 & 30,3 \\
S1 Keperawatan + Ners & & \\
\hline Lama Kerja & 12 & 40,0 \\
\hline 2 - 3 Tahun & 18 & 60,0 \\
4-5 Tahun & 30 & 100,0 \\
Total & &
\end{tabular}

Tabel 2

Distribusi Frekuensi Responden Berdasarkan Pelaksanaan Pendekatan Family Centered Care Pada Pasien Anak dan Kepuasan Kerja Perawat

\begin{tabular}{ccl}
\hline Pendekatan Family Centered Care & $\mathrm{f}$ & $\%$ \\
\hline Baik & 12 & 40,0 \\
Kurang Baik & 18 & 60,0 \\
Total & 30 & 100,0 \\
\hline
\end{tabular}

Tabel 3

Disitribusi Frekuensi Responden Berdasarkan Kepuasan Kerja Perawat di Ruang Perawatan Mawar RSUD. H. A. Sulthan Daeng Radja Kabupaten Bulukumba

\begin{tabular}{ccc}
\hline Kepuasan Kerja Perawat & f & $\%$ \\
\hline Puas & 16 & 53,3 \\
Tidak Puas & 14 & 46,7 \\
Total & 30 & 100,0
\end{tabular}


Tabel 4

Analisis Hubungan Antara Pendekatan Family Centered Care Pada Pasien Anak Dengan Kepuasan Kerja Perawat

\begin{tabular}{ccccccccc}
\hline & \multicolumn{3}{c}{ Kepuasan Kerja Perawat } & \multicolumn{2}{c}{ Total } & $P$ \\
\hline $\begin{array}{c}\text { Pendekatan Family } \\
\text { Centered Care }\end{array}$ & \multicolumn{2}{c}{ Puas } & \multicolumn{2}{c}{ Tidak Puas } & & & \\
\cline { 2 - 6 } & F & $\%$ & f & $\%$ & f & $\%$ & \\
\hline Baik & 2 & 6,6 & 10 & 33,3 & 12 & 40,0 & \\
& 1 & & & & & & 0,001 \\
Kurang Baik & 4 & 46,7 & 4 & 13,3 & 18 & 60,0 & \\
Total & 1 & & & & & & \\
\hline
\end{tabular}

